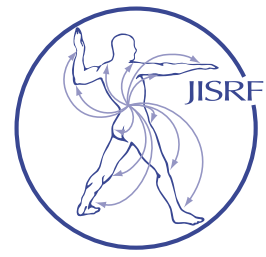

\title{
Dual Antibiotic Therapy with Vancomycin and Cefazolin for Surgical Prophylaxis in Total Knee Arthroplasty
}

\author{
Cohen-Rosenblum $A^{1}$, Crutcher $M^{1}$, Gui ${ }^{1}$, Novicoff $W^{1}$, Nelson $S^{1}$, Browne $J A^{1}$
}

\section{Abstract}

Background: Perioperative administration of intravenous antibiotics is a routine part of total knee arthroplasty. Antibiotic selection is a matter of controversy, and the potential risks and benefits associated with each antibiotic selection need to be considered. The objective of this study is to examine the effects of routine dual antibiotic prophylaxis with both cefazolin and vancomycin on infection and renal failure after primary total knee arthroplasty (TKA) compared with cefazolin alone.

Methods: We performed a retrospective review of primary TKA patients for two years before and two years after routine dual antibiotic prophylaxis was implemented at our institution. 1502 patients were included (567 cefazolin-only and 935 dual prophylaxis).

Results: 2 patients $(0.4 \%)$ in the cefazolin-only group had a deep surgical site infection, compared with 13 patients $(1.4 \%)$ in the dual prophylaxis group $(\mathrm{p}=0.06) .46$ patients $(8.1 \%)$ in the cefazolin-only group had postoperative renal failure, compared with 36 patients $(3.9 \%)$ in the dual prophylaxis group ( $\mathrm{p}=0.0006)$.

Discussion and Conclusion: Our results did not support the routine use of vancomycin in primary total joint arthroplasty to decrease periprosthetic joint infection. However, we also did not see any clear harm due to renal failure in the routine use of dual antibiotic prophylaxis.

\section{Background}

Since its controversial introduction over 50 years ago, perioperative administration of intravenous antibiotics has become a routine part of total joint arthroplasty and is proven to reduce the risk of infection [1-4] . The recommended number and combination of specific antibiotics continues to be a matter of debate. The 2013 Proceedings of the International Consensus on Periprosthetic Joint Infection found a strong consensus that a first or second-generation cephalosporin should be used for routine surgical prophylaxis, as well as strong consensus against the routine use of vancomycin given the lack of convincing evidence available [ $[$ ] However, with the increased prevalence of methicillin-resistant Staphylococcus aureus (MRSA) having emerged over the past 2 decades, vancomycin is increasingly used for prophylaxis in primary and revision total joint arthroplasty [ $\underline{6}-\underline{9}]$.

Vancomycin is a glycopeptide antibiotic that inhibits bacterial cell wall synthesis, and has been found to be effective in the prevention of MRSA surgical site infections [10]. It is commonly used for surgical prophylaxis for patients with a ß-lactam allergy or MRSA colonization, either alone or in combination with another antibiotic with

Keywords: antibiotic prophylaxis; primary total knee arthroplasty; infection; renal failure

Level of Evidence: AAOS Therapeutic Level III 
broader coverage such as clindamycin or an aminoglycoside [10-12]. However, vancomycin has relatively weak antibacterial activity against methicillin-sensitive Staphylococcus aureus (MSSA). Vancomycin is also associated with nephrotoxicity and ototoxicity, as well as the development of vancomycin-resistant enterococci $[\underline{13}, \underline{14}]$. A 2015 study found that total joint arthroplasty patients receiving dual antibiotic prophylaxis with vancomycin and cefazolin had a higher incidence of acute kidney injury than those treated with cefazolin only [15].

There are relatively few studies comparing antibiotic prophylaxis with cefazolin alone with routine dual prophylaxis with cefazolin and vancomycin in total joint arthroplasty. A 2012 retrospective review by Sewick et al. of almost 2000 primary total joint arthroplasty patients found no reduction in surgical site infections after the addition of vancomycin to cefazolin for surgical prophylaxis [16]. A 2018 retrospective review of neary 1900 patients by Burger et al. found that the addition of vancomycin to cefazolin at least 45 minutes prior to skin incision reduced deep infection rates in primary hip and knee arthroplasty with a low risk of renal impairment [17].

Given the potential risks of vancomycin administration and the relative paucity of comparative data, the purpose of this study was to investigate infection rates and nephrotoxicity in total knee arthroplasty patients before and after the adoption of routine dual-antibiotic prophylaxis by our institution. Our hypothesis was that there would be a decrease in periprosthetic joint infection and an increase in acute kidney injury during the dual prophylaxis period.

\section{Materials and Methods}

Following Institutional Review Board approval, we retrospectively reviewed all patients who had undergone primary total knee replacements performed from January 2010 to June 2014. In July 2012 our institutional protocol switched from using cefazolin alone to dual-antibiotic prophylaxis with cefazolin and vancomycin for total joint arthroplasty, allowing the division into two groups: 1) cefazolin only and 2) vancomycin and cefazolin. Primary total knee arthroplasty patients from this time period receiving a different combination of antibiotics were excluded. Prior to incision, patients in the cefazolin-only group received a weight-based dose of cefazolin, with patients less than $70 \mathrm{~kg}$ receiving $1 \mathrm{~g}, 70-120 \mathrm{~kg}$ receiving $2 \mathrm{~g}$, and over $120 \mathrm{~kg}$ receiving $3 \mathrm{~g}$. Those in the dual prophylaxis group received a weight-based dose of cefazolin and 1 gram of vancomycin. Both groups received 2 additional doses of intravenous cefazolin in a 24-hour period starting 8 hours after the procedure. No additional postoperative dose of vancomycin was given to patients in the dual prophylaxis group.

Electronic medical records were reviewed for age, sex, ethnicity, body mass index (BMI), American Society of Anesthesiologists (ASA) class, pre and post-operative creatinine, readmission within 90 days, return to the operating room for another procedure, and occurrence of superficial or deep surgical site infection. Surgical site infection was defined according to the World Health Organization definition as "infections anatomically associated with a surgical procedure performed in an operating room and not present prior to the operation" [18]. Superficial surgical site infection (SSI) was considered to have occurred in any patient with abnormal superficial incisional signs such as redness or swelling, prolonged drainage, or for whom the surgeon administered any postoperative oral antibiotics. This diagnosis of SSI was made by the individual attending surgeon based upon clinical experience. Deep infection was considered to have occurred in any patient returned to the operating room in the 90-day postoperative period for hematoma, drainage, wound dehiscence, or purulence. A culture-negative deep infection was defined as a periprosthetic infection that had met Musculoskeletal Infection Society criteria for periprosthetic joint infection without positive cultures [19]. Patients with an elevation in postoperative creatinine were subcategorized into different stages of renal failure according to the Acute Kidney Injury Network staging system from 1 to 3 [20].

Statistical analysis of the two groups was performed using Pearson's chi-square test. In addition, logistic regression was used to control for demographic differences between groups. Power analysis showed that we needed at least 435 patients in each group to be able to detect a $50 \%$ difference in infection rates between groups (combining superficial and deep infections) with $80 \%$ power.

\section{Results}

1502 primary total knee arthroplasty patients were included in the study, with 567 patients in the cefazolin-only group (65.4\% female) and 935 patients (63.0\% female) in the cefazolin and vancomycin group. Complete demographic data is shown in Table 1.58 patients $(10.2 \%)$ in the cefazolin-only group had a superficial surgical site infection, compared with 86 patients $(9.2 \%)$ in the cefazolin and vancomycin group $(\mathrm{p}=0.53) .2$ patients $(0.4 \%)$ in the cefazolin-only group had a deep surgical site infection, compared with 13 patients (1.4\%) in the cefazolin and vancomycin group ( $\mathrm{p}=0.06)$. The 2 deep infections in the ce- 
Table 1. Group Characteristics of TKA Patients, 2010-2014

\begin{tabular}{|c|c|c|c|c|c|}
\hline & \multicolumn{2}{|c|}{$\begin{array}{c}\text { Cefazolin Only } \\
(n=567)\end{array}$} & \multicolumn{2}{|c|}{$\begin{array}{c}\text { Cefazolin and } \\
\text { Vancomycin }(n=935) \\
\end{array}$} & \multirow[t]{2}{*}{ p-value } \\
\hline & $\mathrm{n}$ & $(\%)$ & $\mathrm{n}$ & $(\%)$ & \\
\hline \multicolumn{6}{|l|}{ Gender } \\
\hline Male & 196 & $(34.6)$ & 346 & $(37.0)$ & $\mathrm{p}=0.347$ \\
\hline Female & 371 & $(65.4)$ & 589 & $(63.0)$ & \\
\hline \multicolumn{6}{|l|}{ Ethnicity } \\
\hline White & 436 & $(76.9)$ & 766 & $(81.9)$ & $\mathrm{p}=0.021$ \\
\hline Black & 89 & $(15.7)$ & 135 & $(14.4)$ & \\
\hline Other & 42 & $(7.4)$ & 34 & $(3.6)$ & \\
\hline \multicolumn{6}{|l|}{ ASA class } \\
\hline 1 & 3 & $(0.5)$ & 7 & $(0.7)$ & $\mathrm{p}=0.000$ \\
\hline 2 & 426 & $(75.1)$ & 591 & $(63.2)$ & \\
\hline 3 & 137 & $(24.2)$ & 332 & $(35.5)$ & \\
\hline 4 & 1 & $(0.2)$ & 5 & $(0.5)$ & \\
\hline \multicolumn{6}{|l|}{ BMI } \\
\hline$<18.0$ & 3 & $(0.5)$ & 1 & $(0.1)$ & $\mathrm{p}=0.020$ \\
\hline $\begin{array}{l}18.0- \\
24.99\end{array}$ & 44 & $(7.8)$ & 121 & (12.9) & \\
\hline $\begin{array}{l}25.00 \text { to } \\
29.99\end{array}$ & 157 & (27.9) & 259 & $(27.7)$ & \\
\hline $\begin{array}{l}30.00 \text { and } \\
\text { higher }\end{array}$ & 359 & (63.8) & 554 & $(59.3)$ & \\
\hline \multicolumn{6}{|l|}{ BMI } \\
\hline $\begin{array}{l}\text { Average } \\
\text { BMI } \pm \text { SD } \\
\text { (standard } \\
\text { deviation) } \\
\end{array}$ & \multicolumn{2}{|c|}{$33.8 \pm 7.5$} & & 6.7 & $\mathrm{p}=0.000$ \\
\hline \multicolumn{6}{|l|}{ Age } \\
\hline $\begin{array}{l}\text { Average } \\
\text { age (years) } \\
\pm \text { SD }\end{array}$ & \multicolumn{2}{|c|}{$62.5 \pm 10.5$} & & 10.2 & $\mathrm{p}=0.572$ \\
\hline
\end{tabular}

fazolin-only group were culture negative. Of the 13 deep infections in the cefazolin and vancomycin group, 4 were culture negative, while the remaining specimens grew positive cultures for methicillin-sensitive Staphylococcus aureus (MSSA) (4 patients), MRSA (2 patients), Streptococcus agalactiae ( 2 patients), Enterobacter cloacae (1 patient), and Escheria coli (1 patient, coinfected with MRSA).

46 patients $(8.1 \%)$ in the cefazolin-only group had postoperative renal failure, compared with 36 patients (3.9\%) in the cefazolin and vancomycin group $(\mathrm{p}=0.0006)$. There were no statistically significant differences in 90-day readmission or return to operating room for further procedures (Table 2). Logistic regression analysis revealed an association between BMI and deep infection ( $\mathrm{p}=0.0146)$, and that female sex, ASA class 1 and 2, and being in the vancomy-
Table 2. Adverse Outcomes of TKA Patients, 2010-2014

\begin{tabular}{|l|cc|cc|c|}
\hline & \multicolumn{2}{|c|}{$\begin{array}{c}\text { Cefazolin Only } \\
(\mathbf{n = 5 6 7 )}\end{array}$} & \multicolumn{2}{|c|}{$\begin{array}{c}\text { Cefazolin and } \\
\text { Vancomycin }(\mathbf{n = 9 3 5})\end{array}$} & p-value \\
\hline & $\mathrm{n}$ & $(\%)$ & $\mathrm{n}$ & $(\%)$ & \\
\hline $\begin{array}{l}\text { Superficial } \\
\text { infection }\end{array}$ & 58 & $(10.2)$ & 86 & $(9.2)$ & 0.5275 \\
\hline $\begin{array}{l}\text { Deep } \\
\text { infection }\end{array}$ & 2 & $(0.4)$ & 13 & $(1.4)$ & 0.0606 \\
\hline $\begin{array}{l}\text { Readmission } \\
\text { within 90 } \\
\text { days }\end{array}$ & 22 & $(3.9)$ & 25 & $(2.7)$ & 0.2215 \\
\hline $\begin{array}{l}\text { Return to } \\
\text { surgery }\end{array}$ & 13 & $(2.3)$ & 16 & $(1.7)$ & 0.4435 \\
\hline $\begin{array}{l}\text { Renal } \\
\text { failure } \\
\text { (stages } \\
\text { merged) }\end{array}$ & 46 & $(8.1)$ & 36 & $(3.9)$ & 0.0006 \\
\hline Stage 1 & 43 & $(7.6)$ & 33 & $(3.5)$ & - \\
\hline Stage 2 & 2 & $(0.4)$ & 2 & $(0.2)$ & - \\
\hline Stage 3 & 1 & $(0.2)$ & 1 & $(0.1)$ & - \\
\hline
\end{tabular}

cin and cefazolin group were protective against postoperative renal failure. Complete results of logistic regression analysis are found in Tables 3 and 4.

\section{Discussion}

We hypothesized that the group receiving dual antibiotic prophylaxis with vancomycin and cefazolin would have a decreased incidence of periprosthetic joint infection and an increase in acute kidney injury compared with the cefazolin group. In fact, somewhat counterintuitively, our data showed a trend towards deep infection in patients receiving dual antibiotic prophylaxis that did not reach statistical significance, as well as a statistically significant decrease in postoperative renal failure.

A review of the existing data involving vancomycin and surgical site infection in total joint arthroplasty shows mixed results. As mentioned previously, the 2012 study by Sewick et al. directly comparing cefazolin monotherapy and dual prophylaxis with vancomycin and cefazolin found no significant change in surgical site infections $(\mathrm{p}=0.636)[16]$. In contrast, the 2018 study by Burger et al. demonstrated a reduced rate of PJI with dual prophylaxis but only when the infusion of vancomycin was administered at least 45 minutes prior to skin incision [17]. Harold et al. and Lamplot et al. both noted a decrease in infection rates when a dual antibiotic approach was incorporated into a multifaceted aseptic protocol to reduce the rates of PJI which also included modified instrument care, preop- 
Table 3: Results of Logistic Regression of TKA Patients with Deep Infection, 2010-2014

\begin{tabular}{|l|l|l|l|}
\hline & p-value & $\begin{array}{l}\text { OR Point } \\
\text { Estimate }\end{array}$ & $\begin{array}{c}\text { OR Confidence } \\
\text { Interval }\end{array}$ \\
\hline $\begin{array}{l}\text { Vancomycin and } \\
\text { cefazolin compared } \\
\text { with cefazolin only }\end{array}$ & 0.0634 & 4.221 & $(0.923,19.306)$ \\
\hline $\begin{array}{l}\text { Female compared } \\
\text { with male }\end{array}$ & 0.6235 & 1.341 & $(0.415,4.331)$ \\
\hline $\begin{array}{l}\text { Ethnicity compared } \\
\text { with white }\end{array}$ & & & \\
\hline Black & 0.9359 & 1.055 & $(0.287,3.877)$ \\
\hline Other & 0.9776 & $<0.001$ & $(<0.001,>999.999)$ \\
\hline $\begin{array}{l}\text { ASA class } 1 \& 2 \\
\text { compared with } 3 \& 4\end{array}$ & 0.2037 & 0.493 & $(0.165,1.468)$ \\
\hline Age & 0.8696 & 1.329 & $(0.044,39.793)$ \\
\hline BMI & 0.0146 & 34.317 & $(2.011,585.638)$ \\
\hline
\end{tabular}

erative nasal mupirocin and altered surgical skin preparation $[\underline{21}, \underline{22}]$.

Smith et al. retrospectively reviewed two groups of primary total joint arthroplasty patients who only received cefazolin and those who only received vancomycin for surgical prophylaxis, and found decreased rates of both periprosthetic joint infection overall and MRSA infection in the vancomycin only group []ㅡ. Ponce et al. retrospectively reviewed over 18,000 primary total joint arthroplasties and found an increased rate of surgical site infection in patients without penicillin allergy receiving vancomycin only for prophylaxis compared with cefazolin only $(2.6 \%$ vs. $1.3 \%, \mathrm{p}<0.01)$. There was no statistically significant difference in the surgical site infection rates for patients receiving vancomycin only compared with vancomycin and cefazolin $(2.6 \%$ vs. $1.6 \%, \mathrm{p}=0.17)$ [23] $]$. Tan et al. found a similar rate of deep infection in primary total joint arthroplasty patients treated with vancomycin monotherapy for ß-lactam allergy compared with non-allergic patients receiving cefazolin, but a comparatively increased risk of Gram-negative infection [24].

Kheir et al. found a higher rate of periprosthetic joint infection in primary total joint arthroplasty patients receiving vancomycin only compared with cefazolin only, noting that only $28 \%$ of the patients in their vancomycin-only group received appropriate weight-based dosing of $15 \mathrm{mg} /$ $\mathrm{kg}$, and that the two periprosthetic infections that occurred in the underdosed group were both caused by MRSA [25]. In our study, all patients receiving dual antibiotic prophylaxis received $1 \mathrm{~g}$ of vancomycin irrespective weight, which likely caused a portion likely caused a portion of patients to be underdosed. This could theoretically explain why the dual prophylaxis group did not have a lower rate
Table 4: Results of Logistic Regression of TKA Patients with Renal Failure, 2010-2014

\begin{tabular}{|l|l|l|l|}
\hline & p-value & $\begin{array}{c}\text { OR Point } \\
\text { Estimate }\end{array}$ & \multicolumn{1}{|c|}{$\begin{array}{c}\text { OR Confidence } \\
\text { Interval }\end{array}$} \\
\hline $\begin{array}{l}\text { Vancomycin and } \\
\text { cefazolin compared } \\
\text { with cefazolin only }\end{array}$ & 0.0001 & 0.400 & $(0.250,0.641)$ \\
\hline $\begin{array}{l}\text { Female compared } \\
\text { with male }\end{array}$ & 0.0001 & 0.381 & $(0.238,0.610)$ \\
\hline $\begin{array}{l}\text { Ethnicity compared } \\
\text { with white }\end{array}$ & 0.2393 & 1.433 & $(0.787,2.609)$ \\
\hline Black & 0.9504 & 1.035 & $(0.355,3.019)$ \\
\hline Other & 0.0027 & 0.477 & $(0.294,0.773)$ \\
\hline $\begin{array}{l}\text { ASA class } 1 \& 2 \\
\text { compared with } 3 \& 4\end{array}$ & 0.1248 & 3.345 & $(0.716,15.636)$ \\
\hline Age & 0.0025 & 6.625 & $(1.943,22.581)$ \\
\hline BMI & & & \\
\hline
\end{tabular}

of infection compared with the cefazolin-only group. Vancomycin underdosing may also have contributed to the low rate of renal failure in the dual prophylaxis group, counter to our hypothesis that there would be an increase in renal failure in patients receiving a potential nephrotoxic medication. In addition, there may have been a selection bias in the dual prophylaxis group against patients at higher risk of renal failure for receiving vancomycin in the first place.

Limitations of this study include its retrospective design and the inclusion of only total knee arthroplasty patients. It is possible that our study is underpowered to show a difference in a relatively rare outcome such as postoperative infection. Also, we did not include close follow-up of postoperative renal failure patients with details such as rate of return to baseline renal function.

\section{Conclusions}

Our results, with the numbers available, did not support the routine use of vancomycin in primary total joint arthroplasty to decrease periprosthetic joint infection. However, we also did not see any clear harm due to renal failure in the routine use of dual antibiotic prophylaxis. Further research should be done to investigate whether routine dual antibiotic prophylaxis with vancomycin should continue to be used routinely for surgical prophylaxis in total joint arthroplasty, or if an algorithm-based antibiotic stewardship program should be adopted to restrict its use to selected subgroups of patients. 


\section{References}

1. American Academy of Orthopaedic Surgeons: Information statement: Recommendations for the use of intravenous antibiotic prophylaxis in primary total joint arthroplasty. AAOS information statement 1027. https://www.aaos.org/uploadedFiles/PreProduction/About/Opinion Statements/advistmt/1027\%20Recommendations \%20for\%20the\%20Use \%20 of\%20Intravenous\%20Antibiotic\%20 Prophylaxis\%20in\%20Primary\%20Total\%20Joint\%20Arthroplasy.pdf Accessed October 14, 2017.

2. Campbell K, Spencer S, Looze C, et al. Antibiotic stewardship in orthopaedic surgery: Principles and practice. J Am Acad Orthop Surg 2014;22:772-81.

3. Bosco J, Bookman J, Slover J, et al. Principles of antibiotic prophylaxis in total joint arthroplasty: Current concepts. J Am Acad Orthop Surg 2015;23:e27-35.

4. Albuhairan B, Hind D, Hutchinson A. Antibiotic prophylaxis for wound infections in total joint arthroplasty: a systematic review. J Bone Joint Surg Br. 2008;90(7):915-19.

5. Parvizi J, Gherke T, Chen AF. Proceedings of the International Consensus on Periprosthetic Joint Infection. Bone Joint J 2013;95-B:1450-2.

6. Klein E, Mojica N, Jiang W, et al. Trends in methicillin-resistant Staphylococcus aureus hospitalizations in the United States, 2010-2014. Clin Infect Dis 2017. doi: 10.1093/cid/cix640

7. Parvizi J, Pawasarat I, Azzam K, et al. Periprosthetic joint infection. J Arthroplasty 2010;25(6):103-7.

8. Smith E, Wynne R, Joshi A, et al. Is it time to include vancomycin for perioperative antibiotic prophylaxis in total joint arthroplasty patients? J Arthroplasty 2012;27(8):55-60.

9. Liu C, Kakis A, Nichols A, et al. Targeted use of vancomycin as perioperative prophylaxis reduces periprosthetic joint infection in revision TKA. Clin Orthop Relat Res 2014;472:227-31.

10. Crawford T, Rodvold K, Solomkin J. Vancomycin for surgical prophylaxis? Clin Infect Dis 2012;54(10):1474-9.

11. Vaisman A, McCready J, Hicks S, et al. Optimizing preoperative prophylaxis in patients with reported ß-lactam allergy: A novel extension of antimicrobial stewardship. J Antimicrob Chemother 2017;72:2657-2660.

12. Bratzler D, Dellinger $\mathrm{P}, \mathrm{Olsen} \mathrm{K}$, et al. Clinical practice guidelines for antimicrobial prophylaxis in surgery. Am J Health-Syst Pharm 2013;70:195-283.

13. Branch-Elliman W, Ripollone J, O'Brien W, et al. Risk of surgical site infection, acute kidney injury, and Clostridium difficile infection following antibiotic prophylaxis with vancomycin plus a beta-lactam versus either drug alone: A national propensity-score-adjusted retrospective cohort study. PLoS Med 2017;14(7):e1002340.

14. Vandecasteele SJ, De Vriese AS, Tacconelli E. The pharmacokinetics and pharmacodynamics of vancomycin in clinical practice: Evidence and uncertainties. J Antimicrob Chemother 2013;68:743-8.

15. Courtney P, Melnic C, Zimmer Z, et al. Addition of vancomycin to cefazolin prophylaxis is associated with acute kidney injury after primary joint arthroplasty. Clin Orthop Relat Res 2015;473:2197-2203.

16. Sewick A, Makami A, Wu C, et al. Does dual antibiotic prophylaxis better prevent surgical site infections in total joint arthroplasty? Clin Orthop Relat Res 2012;470:2702-7.

17. Burger J, Hansen B, Leary E, Aggarwal A, Keeney J. Dual-Agent Antibiotic Prophylaxis Using a Single Preoperative Vancomycin Dose Effectively Reduces Prosthetic Joint Infection Rates With Minimal Renal Toxicity Risk. J Arthroplasty. 33 (2018) S213-S218
18. WHO Surgical Site Infection Prevention Guidelines. http://www.who.int/gpsc/appendix13.pdf, accessed 2/11/18.

19. Parvizi J, Zmistowski B, Berbari E, et al. New definition for prosthetic join infection: From the workgroup of the Musculoskeletal Infection Society. Clin Orthop Relat Res 2012;469:2992-4.

20. Classification/Staging System for Acute Kidney Injury. http://www.akinet.org/ akinstudies.php, accessed 2/11/18.

21. Harold RE, Butler BA, Lamplot J, Luu HH, Lawton CD, Manning D. Multifaceted aseptic protocol decreases surgical site infections following hip arthroplasty. Hip Int 2017. https://doi.org/10.5301/hipint.500055.

22. Lamplot JD, Luther D, Mawdsley EL, Luu HH, Manning D. Modified protocol decreases surgical site infections after total knee arthroplasty. J Knee Surg 2015;28:395e403.

23. Ponce B, Raines BT, Reed R, et al. Surgical site infection after arthroplasty: Comparative effectiveness of prophylactic antibiotics. Do Surgical Care Improvement Project Guidelines need to be updated? J Bone Joint Surg Am 2014;96:970-7.

24. Tan T, Springer B, Ruder J, et al. Is vancomycin-only prophylaxis for patients with penicillin allergy associated with increased risk of infection after arthroplasty? Clin Orthop Relat Res 2016;474:1601-6.

25. Kheir M, Tan T, Azboy I, et al. Vancomycin prophylaxis for total joint arthroplasty: Incorrectly dosed and has a higher rate of periprosthetic infection than cefazolin. Clin Orthop Relat Res 2017;475:1767-74.

\section{SUBMISSION HISTORY}

Submitted August 22, 2018

Reviewed November 9, 2018

Accepted November 20, 2018

Published December 31, 2018

\section{AUTHOR AFFILIATIONS}

1 Anna Cohen-Rosenblum, MD; Madison Crutcher, MD; Jane Gui; Wendy Novicoff, PhD; Stephen Nelson, MD; James A Browne, MD University of Virginia, 190 McCormick Rd, Charlottesville, VA 22903

(Direct inquires to Stephen Nelson, sn4rq@hscmail.mcc.virginia.edu)

\section{AUTHOR DISCLOSURES}

The authors declare that there are no disclosures regarding the publication of this paper.

\section{COPYRIGHT \& OPEN ACCESS}

(C) 2018 Rosenblum, Crutcher, Gui, Novicoff, Nelson, Browne. All rights reserved. Authors retain copyright and grant the journal right of first publication with the work. Reconstructive Review is an open access publication and follows the Creative Commons Attribution-NonCommercial CC BY-NC. This license allows anyone to download works, build upon the material, and share them with others for non-commercial purposes as long as they credit the senior author, Reconstructive Review, and the Joint Implant Surgery \& Research Foundation (JISRF). An example credit would be: "Courtesy of (senior author's name), Reconstructive Review, JISRF, Chagrin Falls, Ohio". 